\title{
Edward C. Benzel: Biomechanics of spine stabilization
}

\section{3rd Edition, Thieme Verlag, New York, Stuttgart, Delhi, Rio, 2015, 568 pp, 1083 illustr., Hardcover, EUR (D) 179,00 EUR (A) 185.10 CHF 207,00, ISBN: 978-1-60406-924-2}

\author{
Pierre Kehr ${ }^{1}$
}

Received: 24 July 2015/ Accepted: 25 July 2015/Published online: 21 August 2015

(C) Springer-Verlag France 2015

This imposing work of biomechanics studies in 39 sections all the methods of stabilization of all the rachidian segments and for all the varieties of lesions and deformities. Enriched by very many diagrams and figures, it justifies the various instrumentations. Each section is the object of many bibliographical references.

True state of the art, the work allows to understand why and how spine osteosyntheses and other implants are indicated. To consult if one wants to avoid the traps and to understand the biomechanical cause of certain failures.

Compliance with ethical standards

Conflict of interest None.

Pierre Kehr

pierre.kehr@gmail.com

1 Strasbourg, France 